\title{
Ongoing large measles outbreak with nosocomial transmission in Milan, northern Italy, March-August 2017
}

A Amendola ${ }^{12}$, S Bianchi ${ }^{1}$, ER Frati ${ }^{1}$, G Ciceri $^{1}$, M Faccini ${ }^{3}$, S Senatore $^{3}$, D Colzani ${ }^{1}$, A Lamberti $^{3}$, M Baggieri $^{4}$, D Cereda ${ }^{5}$,

M Gramegna ${ }^{5}$, L Nicoletti ${ }^{4}$, F Magurano ${ }^{4}$, E Tanzi ${ }^{12}$

1. Department of Biomedical Sciences for Health, University of Milan, Milan, Italy

2. Coordinated Research Center 'EpiSoMl', University of Milan, Milan, Italy

3. Health Protection Agency, Metropolitan Area of Milan, Milan, Italy

4. National Reference Laboratory for Measles and Rubella, Istituto Superiore di Sanità, Rome, Italy

5. DG Salute, UO Governo della prevenzione e tutela sanitaria, Lombardy Region, Milan, Italy

Correspondence: Antonella Amendola (antonella.amendola@unimi.it)

Citation style for this article:

Amendola A, Bianchi S, Frati ER, Ciceri G, Faccini M, Senatore S, Colzani D, Lamberti A, Baggieri M, Cereda D, Gramegna M, Nicoletti L, Magurano F, Tanzi E. Ongoing large measles outbreak with nosocomial transmission in Milan, northern Italy, March-August 2017. Euro Surveill. 2017;22(33):pii=30596. D0I: http://dx.doi.

org/10.2807/1560-7917.ES.2017.22.33.30596

Article submitted on 27 July 2017 / accepted on 10 August 2017 / published on 17 August 2017

A large measles outbreak has been ongoing in Milan and surrounding areas. From 1 March to 30 June 2017, 203 measles cases were laboratory-confirmed (108 sporadic cases and 95 related to 47 clusters). Phylogenetic analysis revealed the co-circulation of two different genotypes, D8 and B3. Both genotypes caused nosocomial clusters in two hospitals. The rapid analysis of epidemiological and phylogenetic data allowed effective surveillance and tracking of transmission pathways.

A large measles outbreak has been ongoing in Milan and surrounding areas, a densely populated area with nearly 4 million inhabitants. Rapid and active surveillance was set up by the Subnational Reference Laboratories (SRL) Milan, established as part of the measles and rubella surveillance network MoRoNet [1] in March 2017, with 303 investigated cases at the time of submission of this report. We present a detailed analysis of the period 1 March to 30 June 2017, with the aim to conduct a complete and rapid characterisation of wild-type measles virus (MV) strains circulating.

\section{Confirmation and investigation of cases} and clusters in Milan

From 1 March to 30 June 2017, 233 suspected cases of measles were investigated: there were 203 (87\%) laboratory-confirmed cases (median age: 30 years; range: 2 months -77 years) and 30 (13\%) were discarded. Overall $60 \%(n=121)$ of the confirmed cases were individuals aged $15-39$ years and $6 \%(n=12)$ were $\leq 1$ year of age; $88 \%(n=179)$ were not vaccinated and $12 \%(n=24)$ were vaccinated (six with two doses of measlesmumps-rubella (MMR) vaccine, 10 with one dose, and eight did not know the number of doses). According to the epidemiological regional database, 108 of 203 were sporadic cases and 95 were related to 47 clusters. Cases were classified as sporadic when an epidemiological link to other cases could not be established.

\section{Molecular surveillance for cases and clusters}

The genotype of MV strains was successfully identified in 187 of 203 (92\%) of the confirmed cases by sequencing the highly variable region of nucleoprotein $(\mathrm{N})$ gene (N-450) [2]. Phylogenetic analysis revealed that the MV strains belonged to genotypes D8 and B3.

The most common genotype detected was genotype D8 ( $86 \% ; 160 / 187$ cases) which was related to 77 cases in 42 clusters and 83 sporadic cases. All of the D8 cases and clusters were autochthonous or from unknown source.

In March 2017, the B3 genotype was detected in five imported cases: two sporadic cases and three cases which subsequently caused three import-related clusters. From April to end of June 2017, a further 14 autochthonous sporadic cases and one cluster were reported. The geographical and temporal distribution, respectively, of sporadic cases and clusters related to D8 and B3 genotypes are shown in Figure 1 and Figure 2.

\section{Measles virus genotype D8}

Phylogenetic analysis showed that all the D8 sequences $(n=160)$ fell into the Osaka lineage (MVi/Osaka. JPN/29.15; similarity range: 99-100\%). From March to May, D8 MV strains mainly caused clusters in work and family settings, which occurred principally in the north-eastern area of Milan. During the week starting 


\section{FIGURE 1}

Geographical distribution of measles cases and clusters, with genotypes, Milan, 1 March-30 June 2017 ( $n=187$ cases)

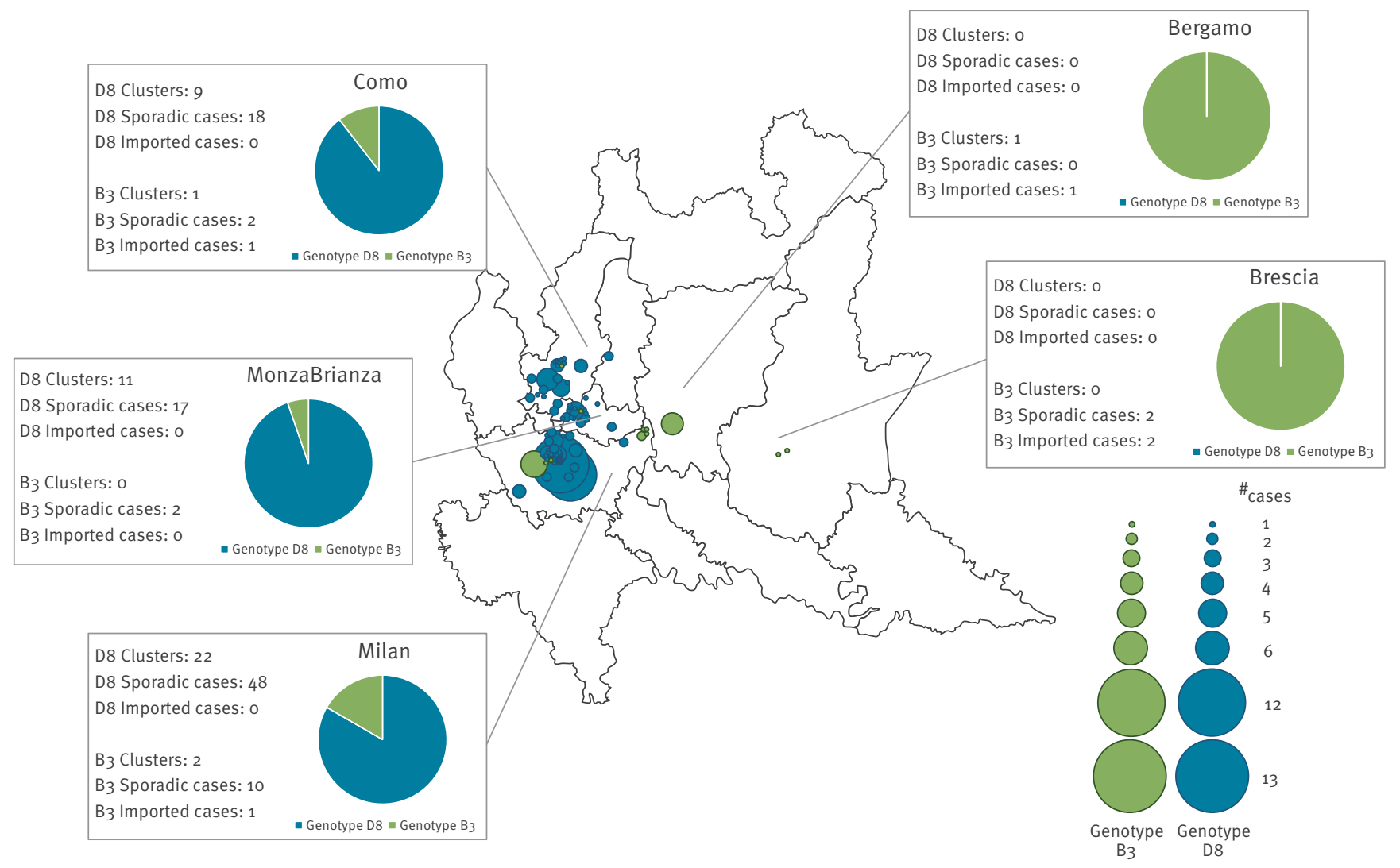

\section{FIGURE 2}

Temporal distribution of measles cases and genotypes detected, Milan, 1 March-30 June 2017 ( $\mathrm{n}=187)$

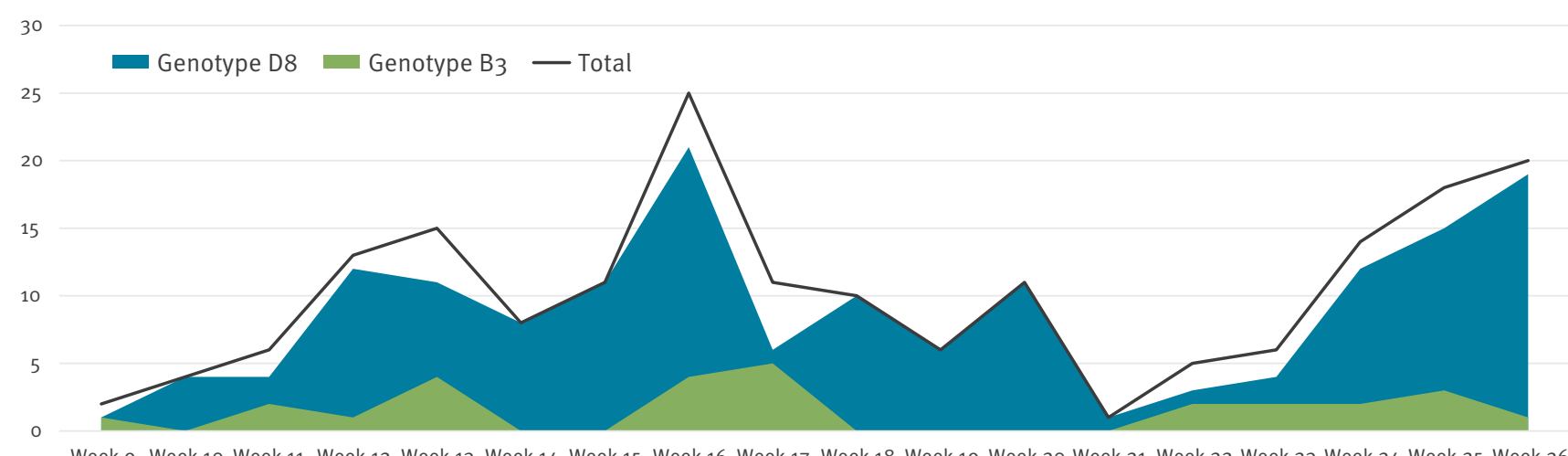

on 27 March 2017, a serious family cluster affected three cases causing the death of one of them. The D8 MV strain was isolated from the biological samples of one of these cases.

In June 2017, the D8 Osaka variant spread through the city of Milan and caused a nosocomial cluster in a hospital. Based on epidemiological data, a link was established between 12 cases: eight healthcare workers (HCWs), three patients and one visitor. Phylogenetic analysis showed that the nine sequences obtained were $100 \%$ identical. The match of epidemiological data and phylogenetic analysis highlighted a single transmission chain for all cases (Figure 3).

\section{Measles virus genotype B3}

Phylogenetic analysis showed that all $B 3$ sequences $(n=27)$ were identical to the variant Dublin (MVs/ Dublin.IRL/8.16; similarity: 100\%) which is circulating in European countries and responsible for an ongoing epidemic in Romania [3]. 
Neighbour-joining tree for nucleotide sequences of measles virus D8 and B3 variants causing nosocomial clusters in two hospitals, Milan, 1 March-30 June $2017(\mathrm{n}=16)$

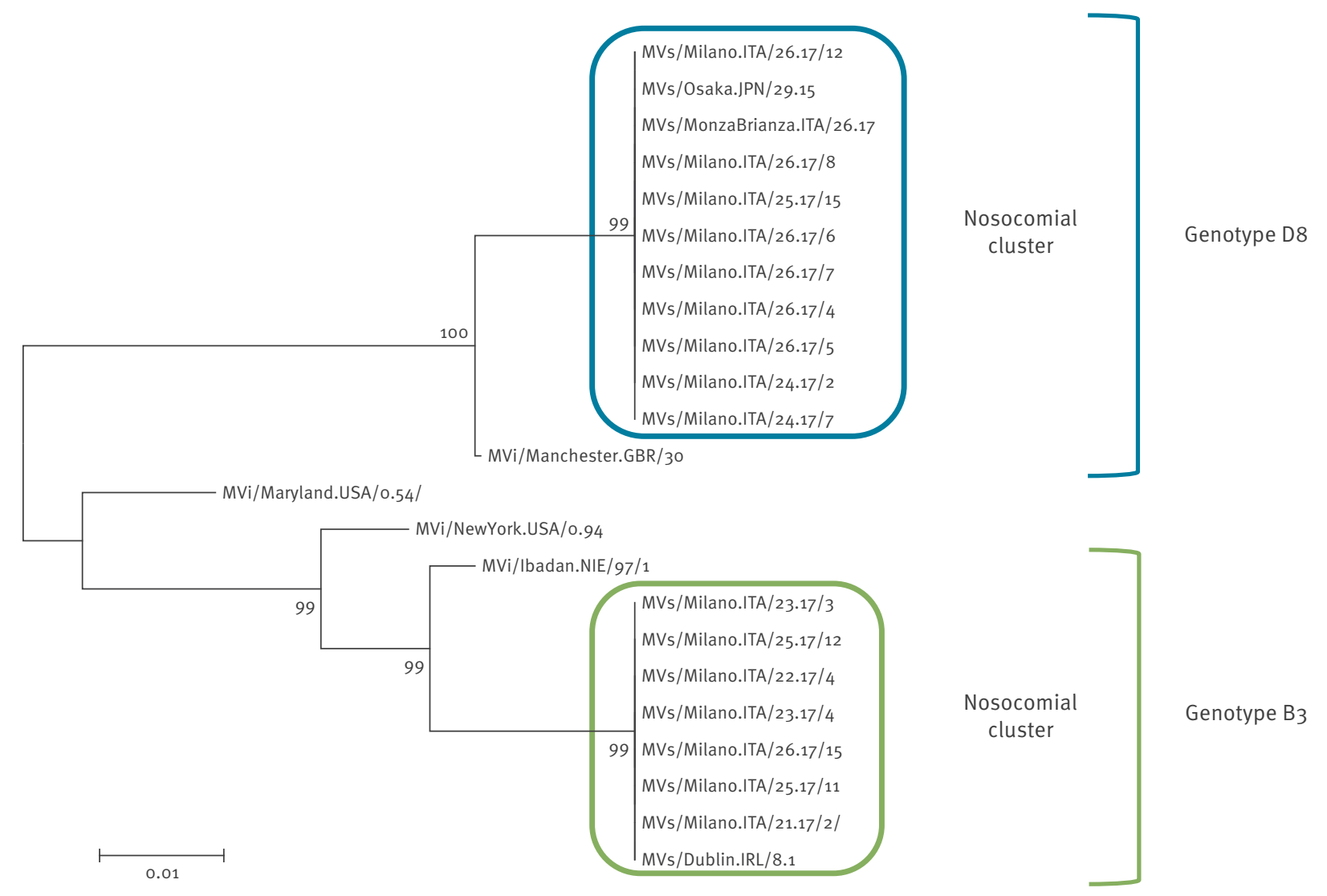

The evolutionary history was inferred using the neighbour-joining method. The evolutionary distances were computed using the Kimura 2-parameter method. Evolutionary analyses were conducted in MEGA6.

The B3 Dublin variant was first introduced in the east of Milan at the beginning of March 2017, and there was an epidemiological link to the Roma community in France. By the end of March, this variant was detected in a sporadic case returning from Piedmont (northern Italy). Subsequently, the same variant was isolated in a cluster caused by an index case returning from the Apulia Region (southern Italy) and in a cluster that was imported from Romania. In April 2017, genotype B3 was identified in a sporadic case returning from the Lazio Region (central Italy).

During May and June 2017, 12 autochthonous cases were notified in the eastern and south-eastern suburbs of Milan. In June, three nosocomial clusters were identified in an emergency department. Although initially reported as unrelated clusters, the phylogenetic analysis showed a single source of transmission ( $n=7$, two HCWs, four patients, and one visitor) (Figure 3).

\section{Conclusions}

Eliminating measles and rubella is a core goal of World Health Organization European Region Member States. Effective surveillance is essential for eliminating measles and rubella and its verification [4]. Since the beginning of 2017 and up to 6 August, the Italian Ministry of Health has reported 4,087 cases of measles and three deaths. Most cases occurred in Piedmont and Lombardy (northern Italy), Tuscany, Lazio and Abruzzo (central Italy) and Sicily (southern Italy). Most were older than 15 years (median age: 27 years) and 89\% of the cases were not vaccinated. Overall, $42 \%$ of the cases were hospitalised and 277 cases were reported among HCWs [5].

Timely measles surveillance is critical to disease control. Identifying and confirming suspected measles cases through surveillance allows early detection of outbreaks and analysis of ongoing transmission in order to mount more effective vaccination measures. MV genotyping can play an important role in tracking transmission pathways during outbreak investigations [6].

From March to June 2017, the genotypes D8 and B3 co-circulated in Milan and surrounding areas. The most common genotype detected was genotype D8, related to 83 sporadic cases and 42 clusters. The high 
similarity between the D8 MV strains, all belonging to the Osaka lineage, suggests a unique initiating transmission event. This is the first evidence of the Osaka D8 variant in northern Italy, which seems to be replacing the D8 variants that had been circulating in this area since $2013[7,8]$.

Moreover, our data show multiple imported cases of $B_{3}$ MV strains which subsequently spread across Italy and caused several autochthonous cases and clusters. The B3 Dublin variant has replaced the B3 variant Como that had been present in this Italian area from August 2015 to November 2016 [9].

By the end of June 2017, D8 MV strains and B3 MV strains had caused clusters in two major Milanese hospitals. In August (current month), the epidemic is still ongoing and the number of notified cases during the month of July was almost twice the number of cases notified in June. Other authors have already reported that where there is evidence of both nosocomial and community transmission of measles, nosocomial transmission appeared to precede community transmission with a peak of hospital-acquired cases occurring almost two weeks before the peak of the community outbreak [10].

In conclusion, the suboptimal immunisation level (92.5\% vaccination coverage rate in Lombardy Region; [11]) and the consequent accumulation of susceptible population have led to an increase in the transmission of measles in northern Italy with detrimental effects on both public health and ongoing measles elimination efforts. Furthermore, the nosocomial outbreaks highlight the importance of improving measles vaccination coverage of healthcare workers.

\section{Acknowledgements}

The authors wish to thank the staff in regional and local health authorities involved in outbreak investigation and reporting of measles cases to the Italian national integrated measles and rubella surveillance system coordinated by the Infectious Diseases Epidemiology Unit of the National Health Institute (Istituto Superiore di Sanità - ISS). They also wish to acknowledge the support of Antonietta Filia, Antonino Bella, Martina Del Manso, Maria Cristina Rota, Paola Bucci and Antonella Marchi at the Department of Infectious Diseases (ISS).

\section{Conflict of interest}

None declared.

\section{Authors' contributions}

A Amendola coordinated virological/epidemiological investigation and laboratory activities and wrote the manuscript. S Bianchi, ER Frati, G Ciceri and D Colzani confirmed measles cases and performed genotyping and phylogenetic analysis of the measles virus sequences isolated from cases in the Lombardy region and interpreted the results. M Faccini, S Senatore, A Lamberti investigated measles cases. M
Gramegna and D Cereda coordinated surveillance and control activities in Lombardy region. F Magurano, M Baggieri, L Nicoletti (MoRoNet National Reference Laboratory) coordinated the virological investigation and supervised phylogenetic analyses. E Tanzi supervised virological/epidemiological investigation and laboratory activities and wrote the manuscript. All the authors reviewed and approved the final manuscript.

\section{References}

1. Istituto Superiore di Sanità (ISS). Mo.Ro.NET: liberi da morbillo e rosolia. [41/5000 Mo.Ro.NET: free from measles and rubella]. Rome: ISS. Accessed July 2017. Italian. Available from: http:// moronetlab.it/

2. Rota PA, Brown K, Mankertz A, Santibanez S, Shulga S, Muller CP, et al. Global distribution of measles genotypes and measles molecular epidemiology. J Infect Dis. 2011;204(1) Suppl 1;S514-23. DOI: 10.1093/infdis/jir118 PMID: 21666208

3. European Centre for Disease Prevention and Control (ECDC). Epidemiological update: Measles - monitoring European outbreaks, 14 July 2017. Stockholm: ECDC; 2017. Available from: https://ecdc.europa.eu/en/news-events/epidemiologicalupdate-measles-monitoring-european-outbreaks-14-july-2017

4. World Health Organization (WHO). Global measles and rubella. Strategic plan 2012-2020. Geneva: WHO; 2012. Available from: http://apps.who.int/iris/ bitstream/10665/44855/1/9789241503396_eng.pdf

5. National Integrated Measles Rubella Surveillance System. Measles in Italy: weekly bulletin. Update as of 06 August 2017. Rome: Istituto Superiore di Sanita. [Accessed: Aug 2017]. Available from: http://www.epicentro.iss.it/problemi/morbillo/ bollettino/Measles_WeeklyReport_N2oeng.pdf

6. Sniadack DH, Crowcroft NS, Durrheim DN, Rota PA. Roadmap to elimination standard measles and rubella surveillance.Wkly Epidemiol Rec. 2017;92(9-10):97-105.PMID: 28262010

7. Amendola A, Bianchi S, Lai A, Canuti M, Piralla A, Baggieri $M$, et al. Measles re-emergence in Northern Italy: Pathways of measles virus genotype D8, 2013-2014. Infect Genet Evol. 2017;48:120-6. DOI: 10.1016/j.meegid.2016.12.013 PMID: 27989661

8. Magurano F, Baggieri M, Filia A, Del Manso M, Lazzarotto T, Amendola A, et al. Towards measles elimination in Italy: Virological surveillance and genotypes trend (2013-2015). Virus Res. 2017;236:24-9. DOI: 10.1016/j.virusres.2017.05.009 PMID: 28522332

9. Filia A, Amendola A, Faccini M, Del Manso M, Senatore S, Bianchi $S$, et al. Outbreak of a new measles B3 variant in the Roma/Sinti population with transmission in the nosocomial setting, Italy, November 2015 to April 2016. Euro Surveill. 2016;21(20):30235. DOI: 10.2807/1560-7917. ES.2016.21.20.30235 PMID: 27240004

10. Botelho-Nevers E, Gautret P, Biellik R, Brouqui P. Nosocomial transmission of measles: an updated review.Vaccine. 2012;30(27):3996-4001. DOI: 10.1016/j.vaccine.2012.04.023 PMID: 22521843

11. Epicentro. Le vaccinazioni in Italia. Rome: Istituto Superiore di Sanita. [Accessed Aug 2017]. Italian. Available from: http:// www.epicentro.iss.it/temi/vaccinazioni/dati_Ita.asp\#morbillo

\section{License and copyright}

This is an open-access article distributed under the terms of the Creative Commons Attribution (CC BY 4.0) Licence. You may share and adapt the material, but must give appropriate credit to the source, provide a link to the licence, and indicate if changes were made.

This article is copyright of the authors, 2017. 